\title{
OPTIMIZATION OF PROCESSING PARAMETERS ON PHYSICAL AND MECHANICAL PROPERTIES OF COPPER-CNT NANOCOMPOSITES
}

\section{VEERANAATH}

Department of Mechanical Engineering, Faculty of Engineering and Technology, SRM Institute of Science and Technology, Kattankulathur, Tamil Nadu, India

\begin{abstract}
Attracting materials like Carbon NanoTubes (CNTs) are proved to be a more promising candidate as the nanodispersion in metal-based nanocomposites. CNTs reinforced in the copper metal matrix is one of the utmost demanding nanocomposites in many industrial applications because of its enhancement in characteristics. But, the hindrance to the enhancement in the properties is the agglomeration of nanoparticles to form clusters and poor interfacial attractions between the constituents. Powder metallurgy is the most common and advantageous fabrication method for these metal matrix nanocomposites. Ball milling and Ultrasonication techniques are methods employed of mechanical blending to evade the growth of clusters. The microstructures of the samples show that the CNTs are homogeneously distributed in some cases which are studied using SEM analysis. The influences of the reinforcement content and manufacturing constraints on the various properties like density, hardness, and Coefficient of Friction (COF) are analyzed and studied. The optimum values of the reinforcement content and process parameters on various outputs are determined using Taguchi and Grey Relation Analysis and ANOVA study is also used to evaluate the role of the governing constraints on the output responses.

KEYWORDS: Nanocomposites, Nanoparticles, Mechanical, Parameters
\end{abstract}

Received: Apr 12, 2020; Accepted: May 03, 2020; Published: May 22, 2020; Paper Id.: IJMPERDJUN202065

\section{INTRODUCTION}

Metal Matrix NanoComposites (MMNCs) are nowadays gaining a lot of curiosity among the manufacturing and speculative investigators because of its wide range of applications. Linked to old-fashioned composites, these nanocomposites yield improved hardness, density, and wear rates along with the friction effect [1]. A wide diversity of metals like aluminum, copper, magnesium, etc. are employed as the binding base metal in MMNCs among which copper is considered to be an interesting candidate as the binding matrix. The cause behind the familiarity of copper is the improved characteristics. And so, even the mechanical features of the copper can be further improved by reinforcing a metal or a ceramic in the copper base which makes it suitable for applications with great scope [2]. Researchers used large number of reinforcements like alumina, silicon carbide, carbon nanotubes, Titanium carbide, Boron carbide, etc. to improve the characteristics of metal matrix alloy. However, Carbon NanoTubes (CNTs) have a special distinction as reinforcement in copper alloy because of its noteworthy properties like high aspect ratio, load-bearing capacity, and conductivity [3]. Thus, by reinforcing CNT in the copper alloy, the nanocomposites which are produced have a great space in growing market demands. There are many fabrications available to produce $\mathrm{Cu}-\mathrm{CNT}$ nanocomposites namely powder metallurgy, stir casting, metal disintegration, etc. Every processing technique has its own merits and demerits. But the powder metallurgy method through mechanical 
alloying route yield more merits compared to others. But the challenges and the problems faced in this method are agglomerations of nanodispersions to form clusters and poor interfacial attractions which may upset the characteristics of the nanocomposites [4]. Many researchers around the universe have tried a lot of means to reduce agglomerations, improve the bonding characteristics, and learn the influence of nanodispersions content on various properties which are focused below.

Ali Samer Muhsan et al. [5] fabricated copper-CNT nanocomposites by fabrication technique name metal injection moulding to homogeneously disperse nanotubes in the matrix which is proved effective using SEM images of the sintered samples. The thermal properties exhibited an upstanding improvement in addition of $1 \mathrm{vol} \%$ of MWCNT which again quoted it as a positive technique for processing. Walid M. Daoush et al. [6] used electrodeless incorporation of the base metal over the exterior of the reinforcement followed by compaction and sintering steps. It was also observed that this method is extra appropriate for the high content of nanotubes in copper as the enhancement in electrical properties is observed. Guiderdoni et al. [7] fabricated CNTs with different numbers of CNT walls and reinforced the same in the copper followed by consolidation in sintering at a high vacuum atmosphere. The double-walled CNT exhibited an improvement in hardness and wear rate in the study. Koti et al. [8] fabricated uncoated and nickel-coated reinforcements using a powder metallurgy route and used TEM images to study the dispersion of reinforcement in the base metal. An improvement in wear rate and friction characteristics were obtained in addition of CNT. Rajyashree et al. [9] highlighted the advantages of electrodeless incorporation of Copper CNT samples to guarantee good interactions. Yan et al. [10] studied the tensile behavior of the various samples in different kinds of nanotube arrangements. Despite these efforts, many researchers focused on it and there is a large area of scope to overcome the limitations faced in the powder metallurgy fabrication process.

Thus, this paper is mainly focused on the fabrication of copper-CNT nanocomposites with powder metallurgy techniques via mechanical alloying processes of ball milling and ultrasonication techniques. The developed nanocomposites were done by employing SEM images to study the dispersion of reinforcements. The effects of reinforcement content and process parameters like processing times on the various outputs like hardness, density, and COF were studied and optimized using Taguchi and Grey Relation Analysis techniques along with ANOVA analysis.

\section{MATERIALS AND METHODS}

Copper $(\mathrm{Cu})$ powders with a purity of $99.15 \%$, the mean size of $25 \mu \mathrm{m}$ and density $8.16 \mathrm{~g} / \mathrm{cm}^{3}$, and CNTs of purity $96 \%, 10-$ $30 \mathrm{~nm}$ in diameter, and $10-35 \mu \mathrm{m}$ were used in this study. The processing techniques include functionalization of CNTs, blending of CNTs, and copper via ball milling and ultrasonication and consolidation. The first stage of functionalization of CNTs is very mandatory to remove unwanted impurities and to attach certain functional group molecules in CNTs to make it easily disperse. The CNTs were functionalized by acid treatment in a magnetic stirrer for 8 hours in a nitric acid solution which is then centrifuged at $10000 \mathrm{rpm}$ for 12 minutes at $20^{\circ} \mathrm{C}$, filtered, and then finally dried at $100^{\circ} \mathrm{C}$ for 3 hours to get in powder form. Then the functionalized CNTs and copper powders are blended in planetary ball milling setup at 250rpm for different times of 60,120 , and 180min with a ball to powder ratio of 10:1. Ethanol is used as a stabilizing agent during the process and WC balls and jars are used for the process. Then the blended samples are then further subjected to the ultrasonication process using probe method for further reducing the agglomeration of reinforcements and dismantling the clusters. The ultrasonication is done for different times of 10, 15, and 20minutes to analyze the influence of the same on various output responses. In the last stage, the blended powder solution is consolidated by drying the same in the oven and 
then compacting and sintering in spark plasma sintering process at a pressure of $50 \mathrm{MPa}$ in a high vacuum state. L9 orthogonal array of design of experiments are taken for the study whose parameter selection is revealed in table 1 wherein the ball milling period and ultrasonication time are varied along with the reinforcement content of 10, 20, and $30 \mathrm{vol} \%$ of the sample. The SEM images were used to study the distribution of the consolidated specimens. The Vickers hardness test is employed to evaluate the microhardness of the specimens, the samples' density is measured based on Archimedes principle and the $\mathrm{COF}$ is determined from sliding wear tests by using the formula $\mu=\mathrm{F} / \mathrm{N}$ where $\mathrm{F}$ is the force induced due to friction and $\mathrm{N}$ is the applied load.

Table 1: Parameter Selection

\begin{tabular}{|l|c|c|c|}
\hline \multicolumn{1}{|c|}{ Parameter } & Level 1 & Level 2 & Level 3 \\
\hline CNT, vol \% & 10 & 20 & 30 \\
\hline Ball Milling Time (min) & 60 & 120 & 180 \\
\hline Ultrasonication Time (min) & 10 & 15 & 20 \\
\hline
\end{tabular}

\section{RESULTS AND DISCUSSIONS}

The various outcomes of the L9 orthogonal experiments namely hardness, density, and COF of the fabricated samples are presented in table 2 .

Table 2: Output Responses of L9 Orthogonal Array of Experiments

\begin{tabular}{|c|c|c|c|c|c|c|}
\hline $\begin{array}{c}\text { Exp. } \\
\text { No. }\end{array}$ & $\begin{array}{c}\text { CNT, } \\
\text { vol \% }\end{array}$ & $\begin{array}{c}\text { Ball Milling } \\
\text { Time (min) }\end{array}$ & $\begin{array}{c}\text { Ultrasonication } \\
\text { Time (min) }\end{array}$ & $\begin{array}{c}\text { Density } \\
(\mathbf{g} / \mathbf{c u . c m})\end{array}$ & $\begin{array}{c}\text { Hardness } \\
(\mathbf{H v})\end{array}$ & $\begin{array}{c}\text { Coefficient of } \\
\text { Friction }\end{array}$ \\
\hline 1 & 10 & 60 & 10 & 8.33 & 83 & 0.52 \\
\hline 2 & 10 & 120 & 15 & 8.15 & 86 & 0.54 \\
\hline 3 & 10 & 180 & 20 & 8.26 & 85 & 0.57 \\
\hline 4 & 20 & 60 & 15 & 7.33 & 76 & 0.48 \\
\hline 5 & 20 & 120 & 20 & 7.78 & 73 & 0.45 \\
\hline 6 & 20 & 180 & 10 & 7.42 & 74 & 0.49 \\
\hline 7 & 30 & 60 & 20 & 7.15 & 71 & 0.41 \\
\hline 8 & 30 & 120 & 10 & 7.23 & 69 & 0.42 \\
\hline 9 & 30 & 180 & 15 & 7.30 & 68 & 0.47 \\
\hline
\end{tabular}

From table 2, it is clear that the maximum density is observed as $8.33 \mathrm{~g} / \mathrm{cu} . \mathrm{cm}$ when compared with pure copper alloy on adding $10 \mathrm{vol} \%$ of CNT because of the dense nature of the reinforcements. But however, on further adding of nanotubes, the dense performance of the nanocomposites reduced on increasing the CNT content which may due to the fact of dispersion of CNTs which is shown in SEM images in figure 1. Similarly, the microhardness of the samples is also improved considerably in addition of CNTs because of the load-standing capacity of the reinforcements and again the same trend is found in hardness also as the density is due to relative density. But the minimum COF is obtained at 30 vol\% of CNT content which may due to reduced wear rate and less force induced in friction. The influence of the various input factors on the responses like is given by mean effect plots of the same as revealed in figure 2. From the SEM images of the sintered nanocomposites, it is clear that the CNTs which are marked in red circles are uniformly distributed in most of the experiment cases but in some places agglomeration and formation of clusters also observed which may be the main reason behind the negative effect on the characteristics of the nanocomposites. 


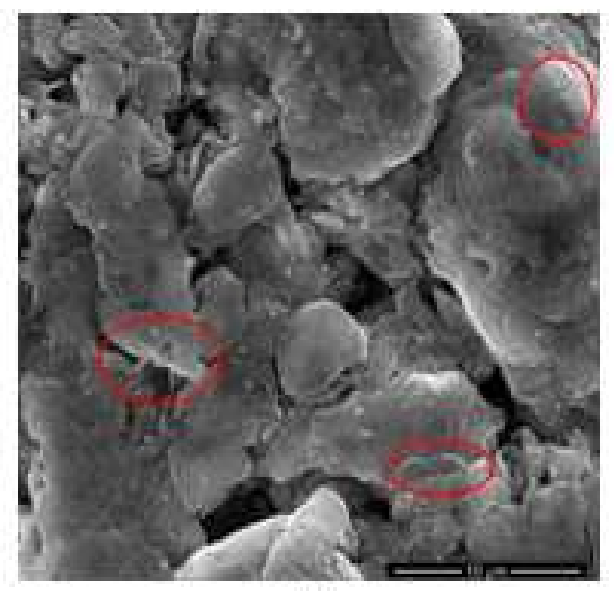

(A)

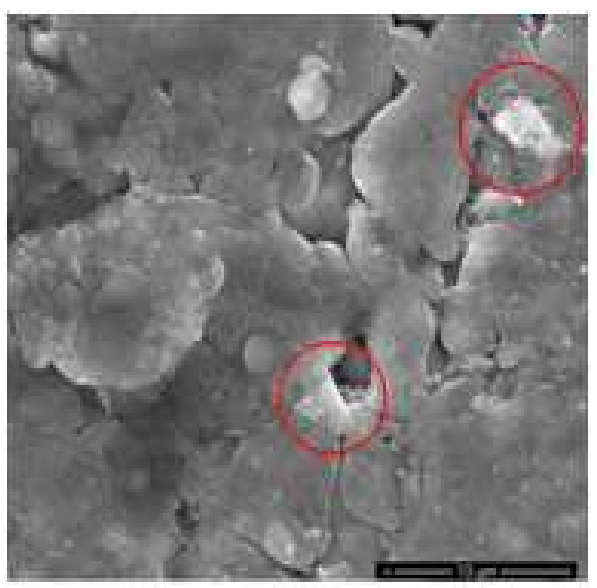

(B)

Figure 1: SEM Images of Cu-CNT Nanocomposites

(A) Experiment No. 1 (B) Experiment No. 4.

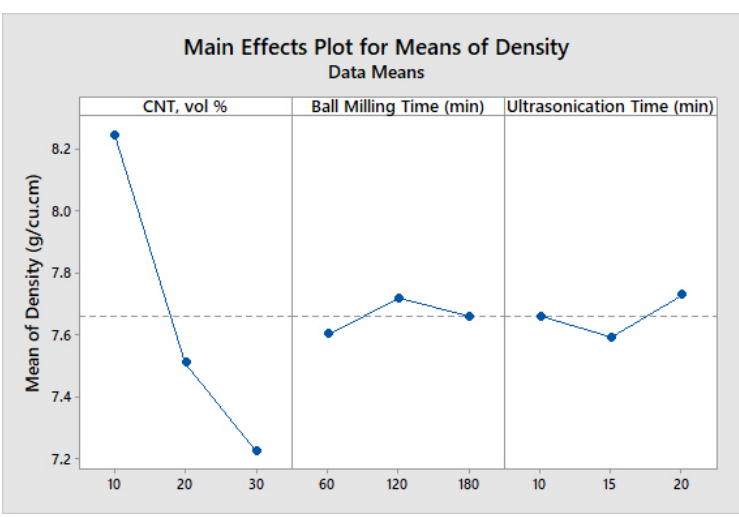

(A)

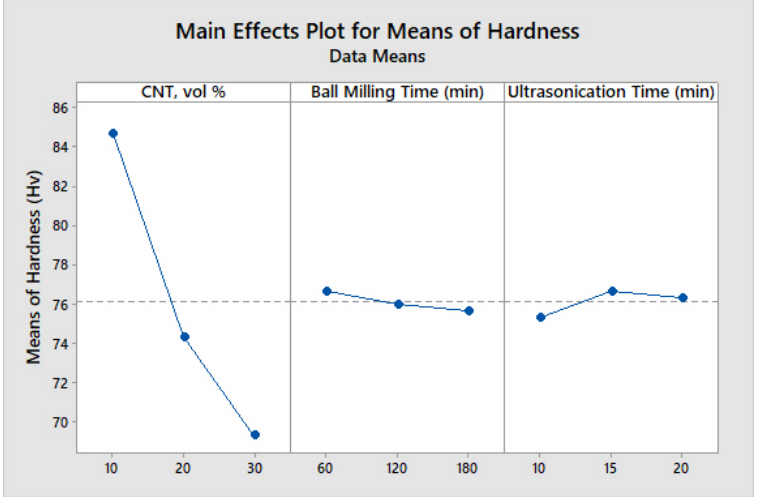

(B)

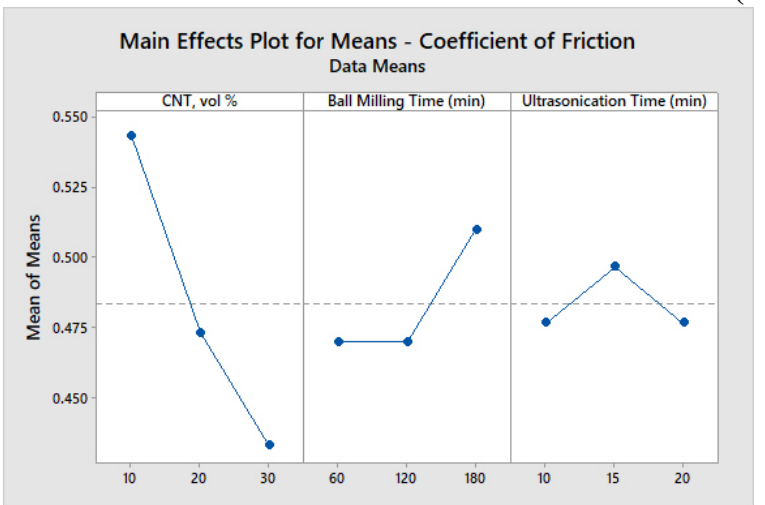

(C)

Figure 2: Mean Effect Plots of the Output Responses (A) Density (B) Hardness (C) Coefficient of Friction.

From the mean effects plots shown in figure 2, it is very evident that all the output responses vary inversely with reinforcement content, that is, the properties fall with a rise in reinforcement content because of the formation of CNT clusters on increasing the content. But for the ball milling period, the density values increase up to 120 minutes, and after which it started to reduce which may due to damage of CNTs which may lessen the characteristics of the same. Similarly, the hardness value also reduced with a rise in the ball milling period as the extensive ball milling might have reduced the length to diameter proportion of the reinforcement which in turn affects the load-standing capacity. And the COF might 
increase after 120 minutes of ball milling because of the reduction in wear rate. On considering ultrasonication time, the hardness and COF reduced after 15 minutes of ultrasonication as more ultrasonication might have damaged the CNT further to reduce the length to diameter proportion and other characteristics of the same.

\section{OPTIMIZATION}

\section{Taguchi Analysis}

In single-objective Taguchi analysis, each output response is analyzed individually to find the best conditions for each response under the various factors. It is done by taking the $\mathrm{S} / \mathrm{N}$ ratio into account and by removing the various noise factors. Here in this study, the input factors are reinforcement CNT content, ball milling time, and ultrasonication time. The main effect plots of $\mathrm{S} / \mathrm{N}$ ratios of various output reactions are presented in figure 3 .

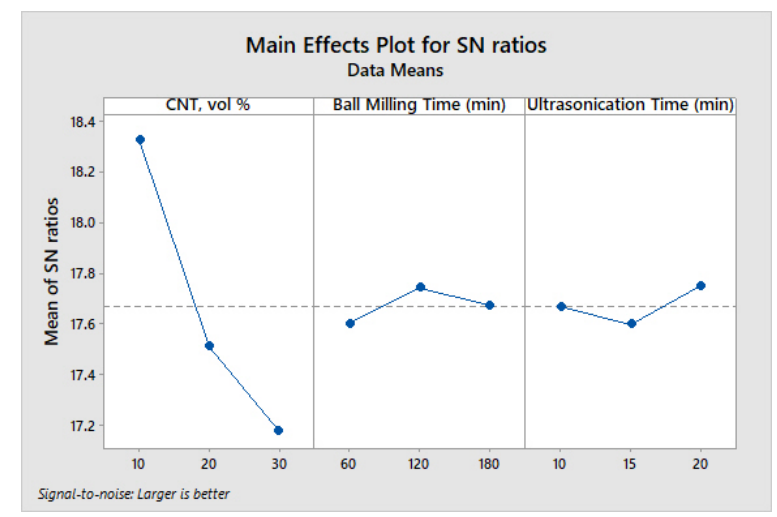

(A)

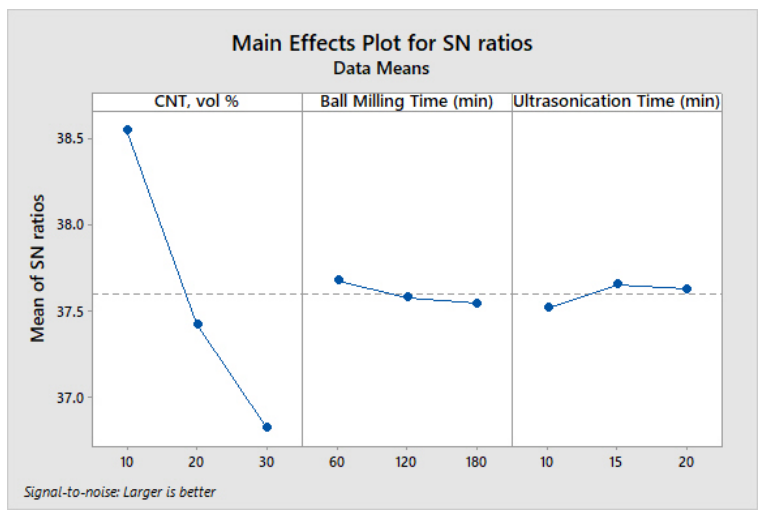

(B)

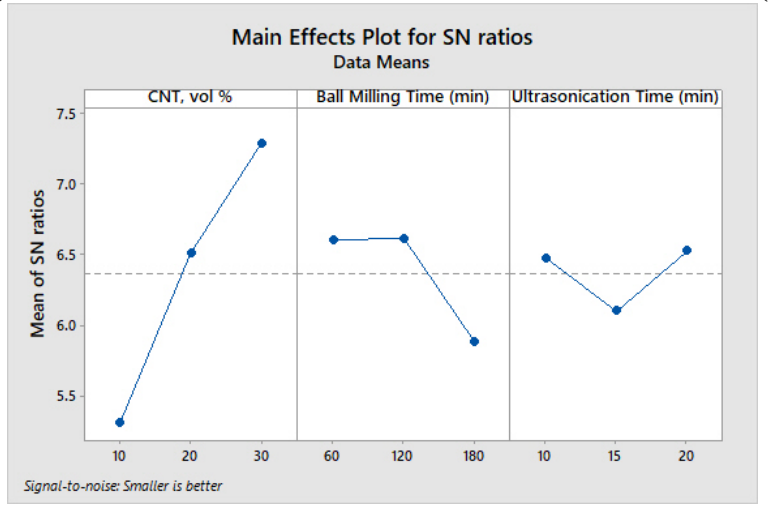

(C)

Figure 3: Analysis of S/N Ratios of the Output Responses

(A) Density (B) Hardness (C) Coefficient of Friction.

The optimum or near optimum conditions of input constraints are predicted relating to the case which has a high $\mathrm{S} / \mathrm{N}$ ratio. In this study, "Larger the better" norms are nominated for hardness and density responses and "Smaller the better" norms for the COF. From figure 3a, it is predicted that maximum density will be obtained at 10vol\% of CNT, $120 \mathrm{~min}$ of ball milling and $20 \mathrm{~min}$ of ultrasonication, from figure $3 \mathrm{~b}$, the maximum hardness is predicted at $10 \mathrm{vol} \%$ of CNT, 60min of ball milling and $15 \mathrm{~min}$ of ultrasonication and from figure $3 \mathrm{c}$, the minimum coefficient friction is predicted $30 \mathrm{vol} \%$ of CNT, 120min of ball milling and 20min of ultrasonication as the corresponding $\mathrm{S} / \mathrm{N}$ values are found to be maximum. The interaction plots of various output responses with the input factors are shown in figure 4. 


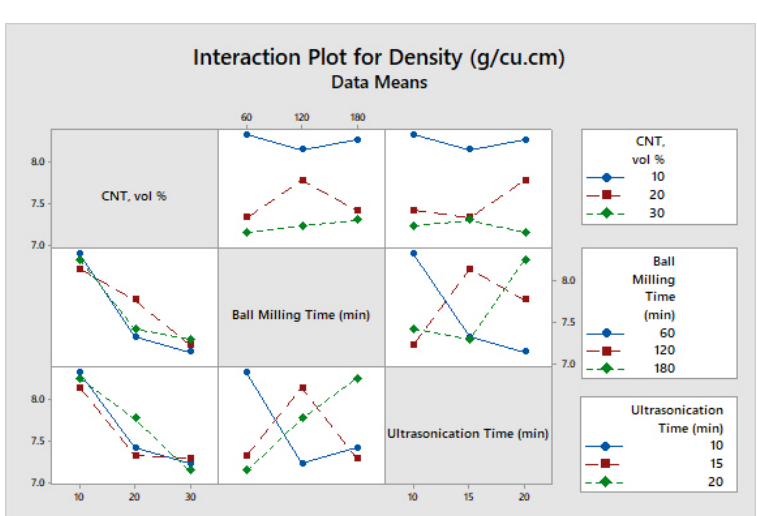

(A)

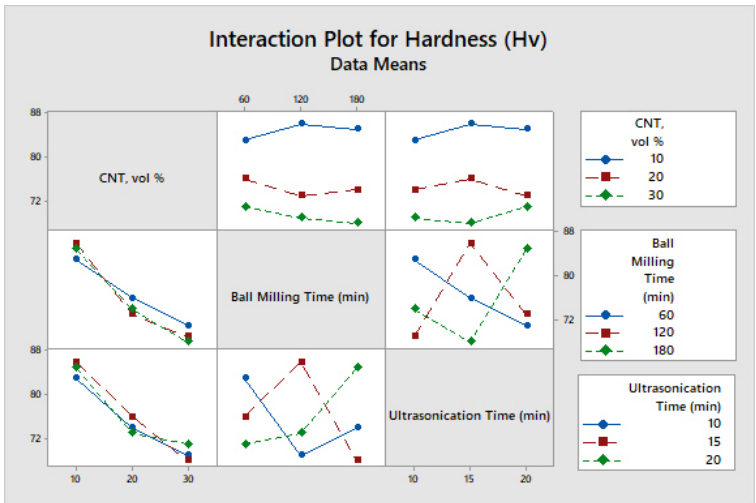

(B)

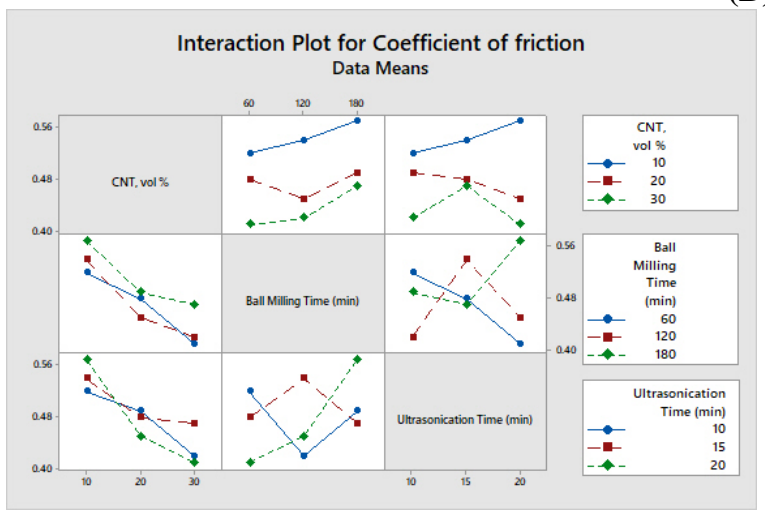

(C)

Figure 4: Interaction Plots of the Output Responses (A) Density (B) Hardness (C) Coefficient of Friction.

From the interaction plots of density, hardness, and COF, it is commonly found that there is no much relationship between CNT, vol\% and the ball milling period, and CNT, vol\% and sonication time but there are more interactions or relation between the ball milling and sonication time as this time has more effect on damaging the CNTs. The damage of CNTs may reduce the aspect ratio which may, in turn, affect the physiognomies of the reinforcement.

Table 3: ANOVA Analysis of Density with $\mathrm{R}-\mathrm{Sq}=\mathbf{9 4 . 8 6}$

\begin{tabular}{|c|c|c|c|c|c|c|c|}
\hline Source & DF & Seq SS & Contribution & Adj SS & Adj MS & F-Value & P-Value \\
\hline CNT, vol \% & 2 & 1.66336 & $92.18 \%$ & 1.66336 & 0.83168 & 17.95 & 0.053 \\
\hline Ball Milling Time (min) & 2 & 0.02042 & $1.13 \%$ & 0.02042 & 0.01021 & 0.22 & 0.819 \\
\hline Ultrasonication Time (min) & 2 & 0.02802 & $1.55 \%$ & 0.02802 & 0.01401 & 0.3 & 0.768 \\
\hline Error & 2 & 0.09269 & $5.14 \%$ & 0.09269 & 0.04634 & & \\
\hline Total & 8 & 1.80449 & $100.00 \%$ & & & & \\
\hline
\end{tabular}

Table 4: ANOVA Analysis of Hardness with R-Sq = 97.49

\begin{tabular}{|l|c|c|c|c|c|c|c|}
\hline \multicolumn{1}{|c|}{ Source } & DF & Seq SS & Contribution & Adj SS & Adj MS & F-Value & P-Value \\
\hline CNT, vol \% & 2 & 366.889 & $96.32 \%$ & 366.889 & 183.444 & 38.4 & 0.025 \\
\hline Ball Milling Time (min) & 2 & 1.556 & $0.41 \%$ & 1.556 & 0.778 & 0.16 & 0.86 \\
\hline Ultrasonication Time (min) & 2 & 2.889 & $0.76 \%$ & 2.889 & 1.444 & 0.3 & 0.768 \\
\hline Error Total & 2 & 9.556 & $2.51 \%$ & 9.556 & 4.778 & & \\
\hline \multicolumn{2}{|c|}{$\quad \mathbf{8 8 0 . 8 8 9}$} & $\mathbf{1 0 0 . 0 0 \%}$ & & & & \\
\hline
\end{tabular}


Table 5: ANOVA Analysis of Coefficient of friction with R-Sq = 99.12

\begin{tabular}{|c|c|c|c|c|c|c|c|}
\hline Source & DF & Seq SS & Contribution & Adj SS & Adj MS & F-Value & P-Value \\
\hline CNT, vol \% & 2 & 0.0186 & $81.58 \%$ & 0.0186 & 0.0093 & 93 & 0.011 \\
\hline Ball Milling Time (min) & 2 & 0.0032 & $14.04 \%$ & 0.0032 & 0.0016 & 16 & 0.059 \\
\hline Ultrasonication Time (min) & 2 & 0.0008 & $3.51 \%$ & 0.0008 & 0.0004 & 4 & 0.2 \\
\hline Error & 2 & 0.0002 & $0.88 \%$ & 0.0002 & 0.0001 & & \\
\hline Total & 8 & 0.0228 & $100.00 \%$ & & & & \\
\hline
\end{tabular}

Tables 3, 4, and 5 presents the ANOVA outcomes of the output responses of density, hardness, and COF respectively. It is recognized that in the situation of density, the major contribution of $92.18 \%$ to the output is from CNT, vol\%, and similarly for hardness and COF also, the major contribution of $96.32 \%$ and $81.58 \%$ is from CNT, vol\% only. This proves that output responses are more dependent on CNT, vol \% rather than the other two dispensation constraints of ball milling and ultrasonication duration as the addition of CNT and agglomeration of the same affects the responses much.

Confirmation experiments are performed to confirm and authorize the predicted results of the Taguchi analysis. So, the experiment is repeated on the ideal conditions of each output response, and individual nanocomposites are built. The predicated and actual values of the confirmation experiments are shown in table 6 below.

Table 6: Confirmation Experiments - Taguchi Analysis

\begin{tabular}{|c|c|c|c|c|c|c|c|}
\hline \multirow{3}{*}{ Response } & \multirow{3}{*}{$\begin{array}{l}\text { CNT, } \\
\text { vol \% }\end{array}$} & \multirow{3}{*}{$\begin{array}{l}\text { Ball } \\
\text { Milling } \\
\text { Time } \\
\text { (min) }\end{array}$} & \multirow{3}{*}{$\begin{array}{l}\text { Ultrasonication } \\
\text { Time (min) }\end{array}$} & \multicolumn{4}{|c|}{ Optimal Conditions } \\
\hline & & & & \multicolumn{2}{|l|}{ S/N Ratio } & \multicolumn{2}{|c|}{ Output Response } \\
\hline & & & & Predicted & Experimental & Predicted & Experimental \\
\hline $\begin{array}{l}\text { Density } \\
\text { (g/cu.cm) }\end{array}$ & 10 & 120 & 20 & 18.475 & 18.413 & 7.66 & 8.34 \\
\hline $\begin{array}{l}\text { Hardness } \\
(\mathrm{Hv})\end{array}$ & 10 & 60 & 15 & 38.676 & 38.68 & 76.11 & 87 \\
\hline $\begin{array}{l}\text { Coefficient } \\
\text { of friction }\end{array}$ & 30 & 120 & 20 & 7.683 & 7.74 & 0.483 & 0.56 \\
\hline
\end{tabular}

\section{GREY RELATION ANALYSIS}

Grey Relation Analysis (GRA) is used for the optimization of multiple output cases wherein the constraints are complicated and by utilizing a concept called grey which shows the deprived and unclear information. Grey relation analysis includes the normalization of the test results, calculating the deviation and grey relational coefficient from which ranking is done. The GRA of the test results is revealed in table 7 and 8 . The normalization of the test results is revealed in Table 7. Deviation, Grey relational coefficient, and rank with Grey Relational Grade (GRG) are revealed in table 8. The mean effects plot of the GRG is revealed in figure 5. Interaction plots of GRGs are revealed in figure 6. ANNOVA analysis of the GRG is presented in table 9.

Table 7: Grey Relational Analysis - Experimental Values \& Normalization

\begin{tabular}{|c|c|c|c|c|c|c|c|c|}
\hline \multirow{2}{*}{$\begin{array}{c}\text { CNT, } \\
\text { Vol } \\
\%\end{array}$} & $\begin{array}{c}\text { Ball } \\
\text { Milling }\end{array}$ & Time & Ultrasonication & \multicolumn{3}{|c|}{ Experimental Values } & \multicolumn{3}{|c|}{ Normalization } \\
\cline { 5 - 9 } & Time (min) & $\begin{array}{c}\text { Density } \\
\text { (g/cu.cm) }\end{array}$ & Hardness & $\begin{array}{c}\text { Coefficient } \\
\text { (Hv) }\end{array}$ & $\begin{array}{c}\text { Density } \\
\text { of Friction }\end{array}$ & $\begin{array}{c}\text { Hardness } \\
\text { (min }\end{array}$ & $\begin{array}{c}\text { Coefficient } \\
\text { (Hv) }\end{array}$ \\
\hline 10 & 60 & 10 & 8.33 & 83 & 0.52 & 0 & 0.1667 & 0.3125 \\
\hline 10 & 120 & 15 & 8.15 & 86 & 0.54 & 0.1525 & 0.0000 & 0.1875 \\
\hline 10 & 180 & 20 & 8.26 & 85 & 0.57 & 0.0593 & 0.0556 & 0 \\
\hline 20 & 60 & 15 & 7.33 & 76 & 0.48 & 0.8475 & 0.5556 & 0.5625 \\
\hline 20 & 120 & 20 & 7.78 & 73 & 0.45 & 0.4661 & 0.7222 & 0.7500 \\
\hline 20 & 180 & 10 & 7.42 & 74 & 0.49 & 0.7712 & 0.6667 & 0.5000 \\
\hline
\end{tabular}


Table 7 Contd,.

\begin{tabular}{|l|c|c|c|c|c|c|c|c|}
\hline 30 & 60 & 20 & 7.15 & 71 & 0.41 & 1.0000 & 0.8333 & 1.0000 \\
\hline 30 & 120 & 10 & 7.23 & 69 & 0.42 & 0.9322 & 1 & 0.9375 \\
\hline 30 & 180 & 15 & 7.3 & 68 & 0.47 & 0.8729 & 1.0000 & 0.6250 \\
\hline
\end{tabular}

Table 8: Grey Relational Analysis - Deviation Sequence, Grey Relational coefficient \& Grade

\begin{tabular}{|c|c|c|c|c|c|c|c|}
\hline \multicolumn{3}{|c|}{ Deviation Sequence } & \multicolumn{3}{|c|}{ Grey Relational Coefficient } & \multirow[b]{2}{*}{ GRG } & \multirow[b]{2}{*}{ Rank } \\
\hline $\begin{array}{l}\text { Density } \\
\text { (g/cu.cm) }\end{array}$ & $\begin{array}{l}\text { Hardness } \\
(\mathrm{Hv})\end{array}$ & $\begin{array}{c}\text { Coefficient of } \\
\text { Friction }\end{array}$ & $\begin{array}{l}\text { Density } \\
\text { (g/cu.cm) }\end{array}$ & $\begin{array}{l}\text { Hardness } \\
(\mathrm{Hv})\end{array}$ & $\begin{array}{c}\text { Coefficient of } \\
\text { Friction }\end{array}$ & & \\
\hline 1 & 0.8333 & 0.6875 & 0.3333 & 0.375 & 0 & 0.3765 & 7 \\
\hline 0.8475 & 1.0000 & 0.8125 & 0.3711 & 0.3333 & 0.3810 & 0.3618 & 8 \\
\hline 0.9407 & 0.9444 & 1 & 0.3471 & 0.3462 & 0.3333 & 0.3422 & 9 \\
\hline 0.1525 & 0.4444 & 0.4375 & 0.7662 & 0.5294 & 0.5333 & 0.6097 & 4 \\
\hline 0.5339 & 0.2778 & 0.2500 & 0.4836 & 0.6429 & 0.6667 & 0.5977 & 5 \\
\hline 0.2288 & 0.3333 & 0.5000 & 0.6860 & 0.6000 & 0.5000 & 0.5953 & 6 \\
\hline 0.0000 & 0.1667 & 0.0000 & 1.0000 & 0.7500 & 1.0000 & 0.9167 & 1 \\
\hline 0.0678 & 0.0556 & 0.0625 & 0.8806 & 0.9000 & 0.8889 & 0.8898 & 2 \\
\hline 0.1271 & 0.0000 & 0.3750 & 0.7973 & 1.0000 & 0.5714 & 0.7896 & 3 \\
\hline
\end{tabular}

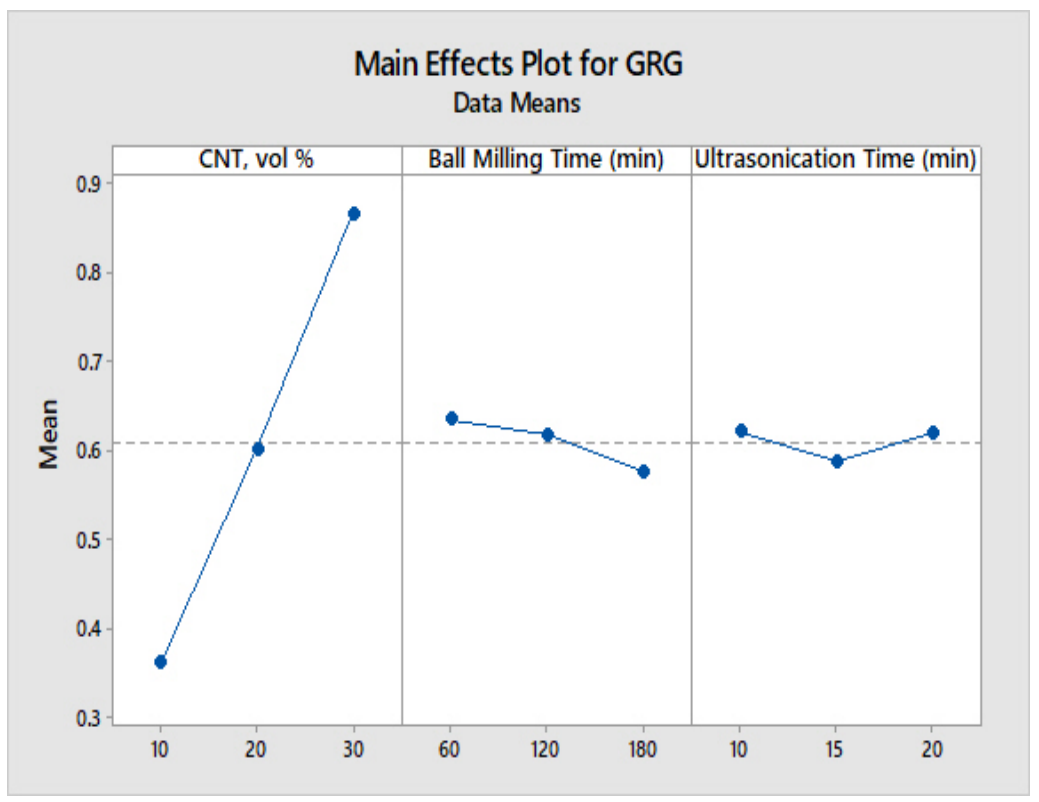

Figure 5: Mean Effect Plots of the GRG. 


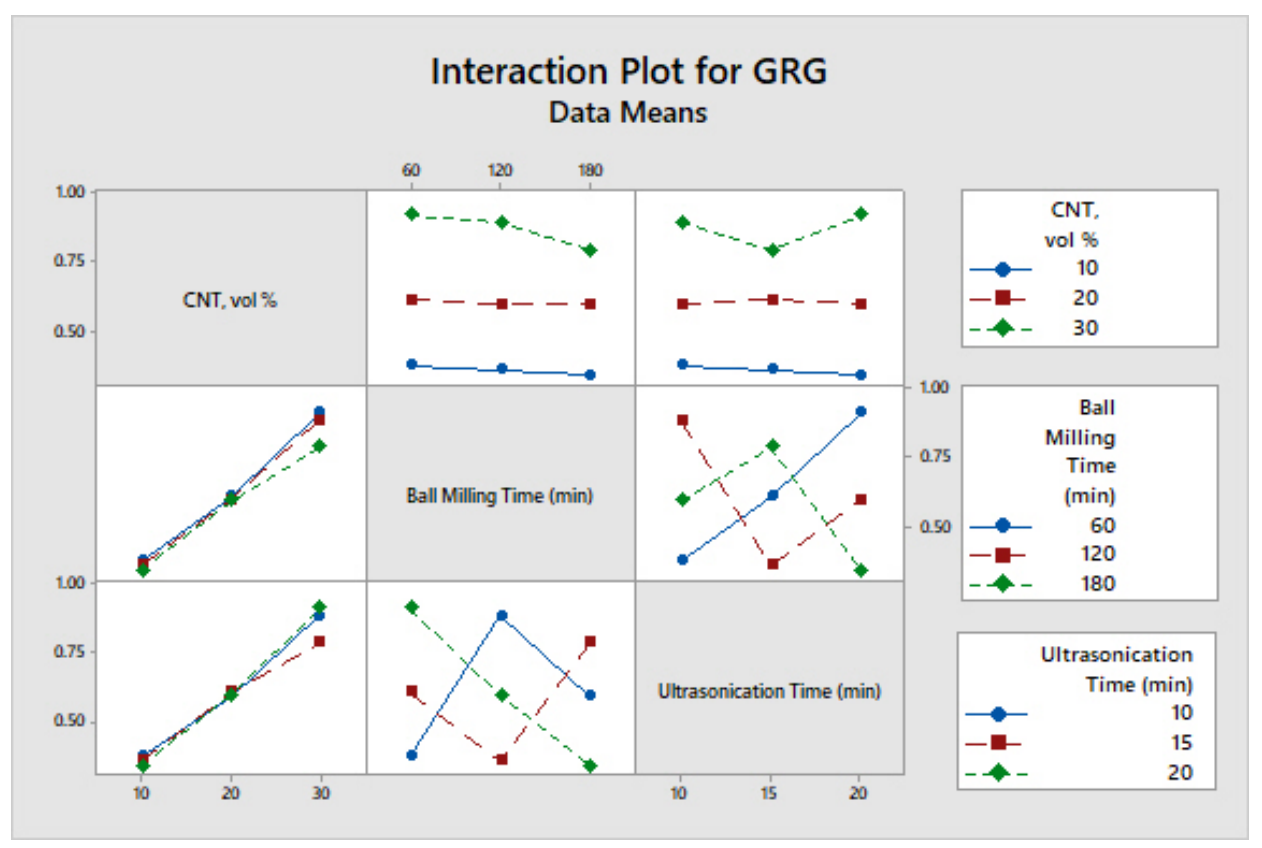

Figure 6: Interaction Plots of the GRG.

Table 9: ANOVA Analysis of GRG with R-Sq = 99.46

\begin{tabular}{|l|c|c|c|c|c|c|c|}
\hline \multicolumn{1}{|c|}{ Source } & DF & Seq SS & Contribution & Adj SS & Adj MS & F-Value & P-Value \\
\hline CNT, vol \% & 2 & 0.383142 & $97.53 \%$ & 0.383142 & 0.191571 & 179.45 & 0.006 \\
\hline Ball Milling Time (min) & 2 & 0.005407 & $1.38 \%$ & 0.005407 & 0.002703 & 2.53 & 0.283 \\
\hline Ultrasonication Time (min) & 2 & 0.002142 & $0.55 \%$ & 0.002142 & 0.001071 & 1 & 0.499 \\
\hline Error Total & 2 & 0.002135 & $0.54 \%$ & 0.002135 & 0.001068 & & \\
\hline \multicolumn{2}{|c|}{$\mathbf{8}$} & $\mathbf{0 . 3 9 2 8 2 6}$ & $\mathbf{1 0 0 . 0 0 \%}$ & & & & \\
\hline
\end{tabular}

From table 8, it is more evident that the conditions of $30 \mathrm{CNT}$, vol \%, 60 min ball milling time, and 20 min ultrasonication time has produced a high rank based on GRG out of the nine experiments. Figure 5 shows the mean effect variation of the GRG with the processing constraints and through which also, the same conditions are observed. The interaction plot shown in figure 6 exhibited that there is more relational or interconnection between ball milling and ultrasonication duration on the grade. As like the output responses, for the GRG also, the more contribution of $97.53 \%$ is from the CNT content only, as shown in table 9. The validation experiment of the above-foretold condition is given in table 10.

Table 10: Confirmation Experiment - Grey Relational Analysis

\begin{tabular}{|l|c|c|}
\hline \multicolumn{1}{|c|}{ Output } & Prediction & Experiment \\
\hline Density (g/cu.cm) & 7.66 & 8.24 \\
\hline Hardness (Hv) & 76.11 & 77.13 \\
\hline Coefficient of friction & 0.483 & 0.513 \\
\hline
\end{tabular}

\section{CONCLUSIONS}

- This paper is mainly concentrated on the fabrication of Copper-CNT nanocomposites by employing hybrid ball milling and ultrasonication approach and the analysis of the influence of the various processing constraints and reinforcement content on various output responses. The output responses like density, hardness, and friction fall 
with a rise in reinforcement content which may be due to the development of CNT clusters on increasing the content.

- From Taguchi analysis, the optimal experiment inputs for best outputs responses were analyzed and confirmation tests were done and the same was validated.. There are also lot of interactions between the input factors of ultrasonication and ball milling time observed in the analysis. And from ANOVA analysis of the results of the Taguchi analysis, it is proved that the output responses are more dependent on CNT content than the other processing constraints. Grey relational analysis is used for multiple objective studies wherein the optimum result is predicted at the case of $30 \mathrm{CNT}$, vol\%, $60 \mathrm{~min}$ ball milling time, and $20 \mathrm{~min}$ ultrasonication time based on grade and ranking. Confirmation experiments are also done to validate the same. From ANNOVA analysis, again $97.53 \%$ dependence is on CNT content.

\section{REFERENCES}

1. Benyamin Abbasipour, Behzad Niroumand, Sayed Mahmoud Monir Vaghefi, Mohammad Abedi (2019). Tribological behavior of A356-CNT nanocomposites fabricated by various casting techniques. Precision Engineering, 29, 1993-2004

2. REDDY, A. CHENNAKEESAVA. "Low and High Temperature Micromechanical Behavior of BN/3003 Aluminum Alloy Nanocomposites." International Journal of Mechanical Engineering and Technology 6.4 (2017): 27-34.

3. Dawid Janas, Barbara Liszka (2017). Copper matrix nanocomposites based on carbon nanotubes or graphene, Materials Chemistry Frontiers

4. M.R. Akbarpour, H. Mousa Mirabad, S. Alipour, H.S. Kim (2019). Enhanced tensile properties and electrical conductivity of $\mathrm{Cu}$-CNT nanocomposites processed via the combination of flake powder metallurgy and high-pressure torsion methods, Materials Science \& Engineering A, 773

5. Habeeb, Majeed A. "Effect of Nanosilver Particles on Thermal and Dielectric Properties of (PVA-PVP) Films." International Journal of Applied and Natural Sciences 2.4 (2013): 103-108.

6. Bruno Faria, Cátia Guarda, Nuno Silvestre, José N.C. Lopes, Diogo Galhofo (2018). Strength and failure mechanisms of cntreinforced copper nanocomposite, Composites Part B, 145, 108-120

7. Belekar, RAJU M., P. S. Sawadh, and R. K. Mahadule. "Synthesis and structural properties of Al2O3ロZrO2 nano composite prepared via solution combustion synthesis." International Journal of Research in Engineering \& Technology, 2, 145152 (2014).

8. Ali Samer Muhsan,Faiz Ahmad, NoraniM.Mohamed, Puteri SriMelor Megat Yusoff, Muhammad Rafi Raza (2013). Uniform Dispersion of Multiwalled Carbon Nanotubes in Copper Matrix Nanocomposites Using Metal Injection Molding Technique, International Journal of Manufacturing Engineering, 2013

9. Bhattacharya, S. S., and S. B. Chaudhari. "Study on structural and thermal properties of polypropylene silica nanocomposite filaments." International Journal of Textile and Fashion Technology 5.1 (2015): 15-22.

10. Walid M. Daoush (2008). Processing and Characterization OF CNT/Cu Nanocomposites by Powder Technology, Powder Metallurgy and Metal Ceramics, 47

11. Ch. Guiderdoni, E. Pavlenko, V. Turq, A. Weibel, P. Puech, C. Estournes, A. Peigney, W. Bacsa, Ch. Laurent (2013). The preparation of carbon nanotube (CNT)/copper composites and the effect of the number of CNT walls on their hardness, friction and wear properties, Carbon, 58, $185-197$ 
12. Vishwanath. Koti1, R. George, Praveennath G. Koppad, K. V. Shivananda Murthy, Ali. Shakiba (2018). Friction and Wear Characteristics of Copper Nanocomposites Reinforced with Uncoated and Nickel Coated Carbon Nanotubes, Materials Research Express

13. Rajyashree M. Sundaram, Atsuko Sekiguchi, Mizuki Sekiya, Takeo Yamada, Kenji Hata (2018). Copper/carbon nanotube composites: research trends and outlook, Royal Society Open Science, 5

14. Yuping Yan, Yinxiang Lei, Sheng Liu (2018). Tensile responses of carbon nanotubes-reinforced copper nanocomposites: Molecular dynamics simulation, Computational Materials Science 151, 273-277

\section{AUTHORS PROFILE}

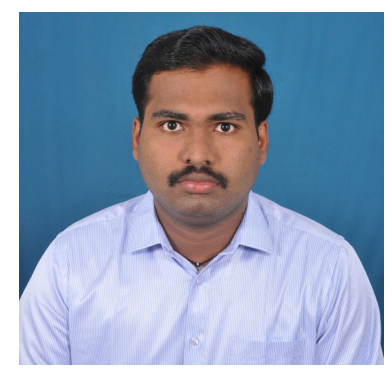

V. Veeranaath is currently working as Assistant Professor in Department of Mechanical Engineering, Faculty of Engineering and Technology, SRM Institute of Science of Technology for the past 5 years. I completed B.Tech (Mechanical Engineering) in Pondicherry Engineering College and M.Tech (Computer Integrated Manufacturing) in SRM University. My research interests are Tool Engineering, Optimization and Nanocomposites. I am a Life time member in International Association of Engineers (IAENG) and Associate Member in Institution of Engineers (IEI). 
